\title{
A POLÍTICA DE EDUCAÇÃO DE ADULTOS INTEGRADA À EDUCAÇÃO PROFISSIONAL NO BRASIL: DAS POLÍTICAS ÀS PRÁTICAS
}

\author{
M. S. MARASCHIN ${ }^{1}$ e L. S. FERREIRA ${ }^{2}$ \\ Colégio Técnico Industrial de Santa Maria ${ }^{1}$, Universidade Federal de Santa Maria ${ }^{2}$ \\ mariglei@ctism.ufsm.br ${ }^{1}$
}

Submetido 14/02/2020 - Aceito 06/04/2020

DOI: $10.15628 /$ holos.2020.9553

\section{RESUMO}

Na última década, a partir do Decreto 5.478/2005, as instituições da Rede Federal brasileiras passaram a ofertar a modalidade de Educação de Jovens e Adultos por força de legislação, pois, anteriormente, algumas já ofertavam por meio de projetos. O presente artigo visa a destacar as principais políticas implementadas pelo governo, através da Secretaria de Educação Profissional e Tecnológica, e discutir como tais políticas se desenvolveram na realidade dos Institutos Federais do Rio Grande do Sul - política de Educação Profissional implementada desde a Lei 11.892/2008. Nessa direção, ancora-se também na visão de que as políticas e práticas de Educação de Jovens e Adultos organizam-se no contexto da dialética das disputas. Para analisar as políticas e as práticas de EJA integrada à EPT, foram produzidos dados a partir de a) pesquisa bibliográfica nas legislações que implementam as políticas e um estudo sobre a realidade dos Institutos Federais do RS; b) entrevistas com gestores dos Institutos; c) grupos focais com estudantes e professores; e d) grupo de interlocução. Os dados, após análise dialética, indicaram significativo investimento nas políticas de EJA na Rede Federal de 2007 a 2010; uma disputa de concepções nas políticas e nas práticas dos cursos implementados e significativas experiências para gestores, professores e estudantes.

PALAVRAS-CHAVE: Políticas de EJA, Políticas de EPT, Institutos Federais, Dialética das Disputas.

\section{THE POLICY OF YOUTH AND ADULT EDUCATION INTEGRATED TO PROFESSIONAL AND TECNOLOGICAL EDUCATION IN BRAZIL: FROM POLICIES TO PRACTICES}

\begin{abstract}
In the last decade, as of Decree 5,478 / 2005, Brazilian federal institutions started to offer the modality of Youth and Adult Education. This article aims to highlight the main policies implemented by the government, through the Secretariat of Professional and Technological Education, and discuss how such policies have developed in the reality of the Federal Institutes of Rio Grande do Sul - Professional Education policy implemented since Law 11.892 / 2008. The policies and practices of Youth and Adult Education are organized in the context of the dialectic of disputes. In order to analyze the policies and
\end{abstract}

practices of EJA integrated to the EFA, data were produced from a) bibliographic research in the laws that implement the policies and a study on the reality of the Federal Institutes of RS; $b$ ) interviews with managers of the Institutes; c) focus groups with students and teachers; and d) interlocution group. The data, after dialectical analysis, indicated a significant investment in EJA policies in the Federal Network from 2007 to 2010; a dispute of conceptions in the policies and practices of the courses implemented and significant experiences for managers, teachers and students

KEYWORDS: Youth and Adult Education policies, Professional and Tecnological Education policies, Federal Institutes, Dialectics of Disputes. 


\section{INTRODUÇÃO}

A EJA, no Brasil, nos últimos anos, apesar de ser reconhecida pela LDB 9394/1996 como modalidade de ensino, tem se configurado como concepções em disputa (Ventura, 2008). Observase uma disputa entre as lógicas de manutenção e superação da ordem social, fragmentação na oferta e precarização na formação de variados e dispersos programas (Ventura, 2008). Sendo assim, é preciso vigilância dos movimentos sociais, demandando o olhar dos governos para a formação e a escolarização dos jovens e adultos, muitas vezes excluídos da escola e do mundo do trabalho.

A partir da eleição do presidente Luís Inácio Lula da Silva, no ano de 2003, os movimentos sociais e fóruns de EJA demandaram ao governo uma política mais intensa para a escolarização dos jovens e adultos e disputaram uma formação aliada à profissionalização. Como a proposta do presidente Lula era um grande investimento em Educação Profissional, em 2005, ele assinou o primeiro Decreto a fomentar que a rede de instituições federais de Educação Profissional passasse a se responsabilizar pela escolarização e profissionalização de jovens e adultos. O primeiro Decreto № 5478/2005 instituiu a oferta de Ensino Médio integrado à Educação Profissional na Rede Federal. Logo, esse decreto foi muito questionado, e o presidente revogou e instituiu o Decreto 5840/2006, que ampliava a oferta na modalidade EJA integrada à EP (Educação Profissional) para toda a Educação Básica e em todas as Redes de Ensino.

Tais decretos intensificaram a presença de jovens e adultos na rede de instituições federais de Educação Profissional brasileiras e o início de uma política de EJA integrada à EPT (Educação profissional e tecnológica) no país. Desde esta legislação, a Rede, mais tarde com enorme expansão ${ }^{1}$, deve ofertar $10 \%$ de suas matrículas na modalidade EJA. Registra-se que, a partir de 2008, a Rede Federal de Educação profissional e Tecnológica passa a configurar-se, em sua maioria, como Institutos Federais de Educação Profissional e Tecnológica.

No Rio Grande do Sul, Estado da região sul do Brasil, existem três Institutos Federais: Instituto Federal Farroupilha, Instituto Sul Rio-Grandense e Instituto Rio Grande do Sul. Os três têm atualmente 42 campi.

Para discutir como as políticas de EJA integradas à EPT - PROEJA - se configuraram na prática, o presente texto, em um primeiro momento, vai apresentar os programas de governo implementados de 2005 a 2015, denominando "a política de Educação de Jovens e Adultos Integrada à Educação Profissional no Brasil" e depois destacar, em seis campus dos Institutos Federais do Rio Grande do Sul, como se desenvolveram as práticas de EJA, intitulando "a realidade das políticas do PROEJA nos Institutos Federais do Rio Grande do Sul".

No que tange aos aspectos metodológicos, o estudo ancora-se na análise dialética, com o intuito de indicar as contradições, a historicidade, a totalidade e a práxis do PROEJA nas realidades

\footnotetext{
${ }^{1}$ Em 2003, eram 140 escolas de Educação Profissional. Atualmente são 644 unidades, conforme site do MEC - acesso em 06/03/2018.
} 
pesquisadas. Esta tem sido um modo de produzir pesquisa em educação no grupo de pesquisa no qual se trabalha, supondo que:

Está-se referindo à expressão "análise dialética", revelando acreditar que engloba o método dialético e o pensamento dialético. Com tal opção pela análise dialética intenciona-se entender os movimentos entre o geral e o particular, entre causas e efeitos, destacando considerações e sistematizações relativas à problematização elaborada e, sobre ela, apresentando alternativas e possibilidades. Portanto, foi além da produção de dados durante a pesquisa bibliográfica, realizando um amplo estudo dos dados, entendendo-os como evidências de sentidos, comparando-os, analisando-os, articulando-os. (Ferreira, 2018, p. 593).

Ademais, como técnica de produção de dados, realizou-se, na primeira fase, pesquisa bibliográfica, entrevistas com gestores e grupos focais com professores e estudantes (Gatti, 2002). Entendeu-se, agindo assim, estar-se-ia produzindo dados em movimentos do individual para o coletivo e de volta àquele. Ao pesquisar nos materiais referentes ao tema, foi possível subsidiar argumentos que as entrevistas e, após, os grupos focais apontaram a partir do campo empírico. Já o grupo de interlocução é um modo de pesquisa desenvolvido pelo grupo de pesquisa ${ }^{2}$, consiste em técnica de análise e produção de dados (Ferreira, Fiorin, Amaral \& Maraschin, 2014) que reúne os pesquisados e pesquisadora e juntos refletem sobre a análise realizada e ainda podem contribuir, questionar e reformular as análises em conjunto. Foi realizado após a primeira fase e consolidou a produção de dados referentes às práticas de EJA nos seis campi pesquisados.

Para o estudo dos dados foi realizada análise dialética, o que exigiu produzir sentidos acerca dos discursos dos interlocutores comparativamente aos textos das políticas educacionais e da literatura acadêmica. Esse movimento somente é possível se realizado comparativamente. Portanto, os discursos foram organizados em tabelas, conforme os sentidos postos em relevo, e comparados entre si e no conjunto. A pesquisa bibliográfica foi uma técnica de produção de dados realizada durante toda a análise para subsidiar os sentidos produzidos. No grupo de interlocução apresentaram-se as primeiras análises e submeteu-as à discussão pelos presentes anteriormente pesquisados, confirmando, refutando e rearticulando sentidos. Com base nesses movimentos, elaborou-se a sistematização de dados, sob a forma deste texto.

A seguir, apresenta-se a sistematização das análises sob a forma de argumentos, visando ao alcance do objetivo do texto, qual seja, contribuir para a análise do modo como as políticas educacionais foram implementadas no PROEJA no âmbito dos Institutos Federais de Educação Profissional e Tecnológica gaúchos. Para tanto, foram organizadas três seções que estão, do ponto de vista temático, articuladas: a primeira aborda as políticas educacionais relativas à EJA e à Educação Profissional no país. As seguintes, com base nos dados produzidos com a pesquisa, analisam a implementação dessas políticas no campo empírico estudado. Seguem considerações finais que visam a alinhavar o estudo realizado até o momento.

\footnotetext{
${ }^{2}$ Está-se referindo ao Grupo Kairós - Grupo de Pesquisas e Estudos sobre Trabalho, Educação e Políticas Públicas da Universidade Federal de Santa Maria.
} 


\section{A POLÍTICA DE EDUCAÇÃO DE JOVENS E ADULTOS INTEGRADA À EDUCAÇÃO PROFISSIONAL NO BRASIL}

O Programa Nacional de Integração da Educação Profissional com a Educação Básica na modalidade de Educação de Jovens e Adultos - PROEJA - foi criado para as instituições federais de educação tecnológica pelo Decreto n. 5.478, de 24 de junho de 2005 e foi expandido para as demais instituições pelo Decreto n. 5.840, de julho de 2006. Essas políticas educacionais visaram a possibilitar e regular a educação dos trabalhadores, cujas idades os classificassem como jovens e adultos, nos níveis inicial e continuado e na Educação Profissional técnica de nível médio, integrada ou concomitante ${ }^{3}$. Embora instituído no âmbito federal, compreendido pela Rede Federal de Educação Profissional, poderá ser adotado pelas instituições públicas dos sistemas de ensino estaduais e municipais e pelo 'Sistema S', desde que se assegure a construção prévia de um projeto pedagógico integrado único (Kuenzer, 2006).

Vale salientar que discutir sobre essa política ${ }^{4}$ de Educação de Jovens e Adultos integrada à Educação Profissional, no Brasil, remete primeiramente a pensar a política de Educação de Jovens e Adultos. Isso porque, por muito tempo, a EJA não ocupou espaço na história das políticas educacionais. Intensificou-se, a partir da Constituição de 1988, o comprometimento do Estado, que enfatizou obrigatoriedade e gratuidade, e da LDB 9394/1996, em que se configurou como modalidade de ensino, estabelecendo o direito a jovens e adultos que não tiveram acesso em idade regular de continuar os estudos no Ensino Fundamental e Médio.

Nessa perspectiva, convém assinalar que a LDB, na constituição da política de EJA, proporciona importante avanço para compreensão dos objetivos, das funções e dos fundamentos das Diretrizes Curriculares Nacionais para a Educação de Jovens e Adultos, estabelecidos pelo Parecer 11/2000. O documento apresenta a EJA como uma grande dívida social:

A Educação de Jovens e Adultos (EJA) representa uma dívida social não reparada para com os que não tiveram acesso a e nem domínio da escrita e leitura como bens sociais, na escola ou fora dela, e tenham sido a força de trabalho empregada na constituição de riquezas e na elevação de obras públicas. Ser privado deste acesso é, de fato, a perda de um instrumento imprescindível para uma presença significativa na convivência social contemporânea (Brasil, 2000, p. 5).

Nesse sentido, percebe-se que a EJA, nos anos 2000, havia avançado significativamente no plano legal das políticas públicas, porém se sabe que os índices brasileiros de sujeitos não escolarizados e em situações de exclusão e desigualdade social eram alarmantes. Por isso, ainda era necessária muita mobilização para que se efetivasse uma política de EJA.

\footnotetext{
${ }^{3}$ A Educação Profissional na Rede Federal de Educação na relação com o Ensino Médio pode se configurar: “[...] concomitante ao ensino médio, em que o estudante pode fazer ao mesmo tempo o ensino médio e um curso técnico, mas com matrículas e currículos distintos, podendo os dois cursos serem realizados na mesma instituição (concomitância interna) ou em diferentes instituições (concomitância externa); a sequencial ou subsequente, destinada a quem já concluiu o ensino médio. (Pacheco, 2012, p.21).

4 Opta-se por referenciar o PROEJA como política, pois mesmo que ele ainda seja visto como "programa", está na LDB através da Lei $N^{\circ} 11.741 / 2008$ e continua presente em muitas instituições, apesar de não ser mais uma política de governo.
} 
Nesse contexto, observa-se que tanto a legislação como a mobilização dos Fóruns de $E J A^{5}$, no Brasil, têm contribuído para a construção de políticas para os sujeitos jovens e adultos. A professora Maria Margarida Machado, no artigo "A educação de jovens e adultos no Brasil pós-Lei no 9.394/96: a possibilidade de constituir-se como política pública", analisa as principais ações para o acesso dos jovens e adultos ao sistema escolar e reconhece que a luta pelo direito à educação implica, além do acesso à escola, na produção do conhecimento no mundo da cultura e do trabalho e nos diversos espaços de convívio social em que os jovens e adultos se constituem como sujeitos.

[...] o resultado da política educacional das últimas décadas focada no atendimento a crianças e adolescentes, reforça a compreensão de que a saída da EJA da marginalidade do sistema educacional, onde ainda se encontra, passa pela superação dessa condição, que é uma produção histórica. Para a maior parte dos jovens e adultos, não há qualquer oferta de educação; quando há, é uma "educação de menor" e, na maioria das vezes, "de muito baixa qualidade" (Machado, 2009, p.28-29).

Reconhece-se, portanto, o papel que os fóruns de EJA assumem na defesa do direito à educação para jovens e adultos excluídos da escola, pois não bastam as legislações e o financiamento, é necessário a permanente inquietação e mobilização dos sujeitos que demandam a EJA. E foi a mobilização e a organização dos fóruns e dos movimentos sociais pelo cumprimento do direito à educação ligados ao contexto da expansão da Educação Profissional que os campos da EJA e da EPT começaram se aproximar e que, por força de legislação, passaram a integrar-se.

Nesse sentido, a integração ocorreu primeiro pelo Decreto 5478/2005, que instituiu, no âmbito das instituições federais de educação tecnológica, o Programa de Integração da Educação Profissional ao Ensino Médio, na modalidade de Educação de Jovens e Adultos. Aqui, nasceu o PROEJA, que é a política que se está analisando. Vale ressaltar o que Manfredi (2002, p. 60) defende: "A Educação Profissional é um campo de disputa e de negociação entre os diferentes segmentos e grupos que compõem uma sociedade, desvelando a dimensão histórico-política das reformas de ensino, das concepções, dos projetos e das práticas formativas."

Também é importante compreender que o PROEJA é visto, neste processo, como dialética das disputas (Maraschin, 2015), isso porque:

[...] a educação para os trabalhadores, as políticas públicas, a Educação Profissional, a Educação de Jovens e Adultos e o trabalho pedagógico ${ }^{6}$ configuram-se e se historicizam em uma dialética de disputas entre diferentes segmentos que ora estão a favor dos trabalhadores; ora têm um discurso

\footnotetext{
${ }^{5}$ A professora Maria Margarida Machado (2009) reconhece a presença dos fóruns de EJA do Brasil nos últimos treze anos, como "organização social, com seus limites e suas potencialidades de atuação e mediação na constituição dessa modalidade como política pública" (Machado, 2009, p. 19-20).

6 "[...] o trabalho dos professores, ao selecionar, organizar, planejar, realizar, avaliar continuamente, acompanhar, produzir conhecimento e estabelecer interações, só possa ser entendido como trabalho pedagógico, imerso em um contexto capitalista, no qual a força de trabalho dos professores é organizada pelas relações de emprego e no qual os sujeitos agem em condições sociais, políticas. Entretanto, ainda que esteja imerso nas relações capitalistas, o trabalho pedagógico, por suas características, apresenta possibilidades de o sujeito trabalhador ir além, projetar-se no seu trabalho de modo a confundir-se e movimentar-se humanamente com ele, uma vez que uma matéria-prima é a linguagem" (Ferreira, 2018, p. 605).
} 
a favor, mas muitas vezes uma prática contraditória. E nesse processo é necessária a vigilância dos movimentos sociais para estar sempre colocando em pauta o direito à educação do trabalhador. (Maraschin, 2015, p. 102-103)

Foi a vigilância dos movimentos sociais, que, logo após o Decreto de 2005, passou a apontar várias falhas neste, e mobilizou-se na luta por outro olhar em relação aos cursos dessa modalidade. Diante de tal mobilização, o governo atendeu às reivindicações ${ }^{7}$ e substituiu o Decreto $\mathrm{n}$ o 5478/2006 pelo Decreto no 5.840, de 13 de julho de 2006, que instituiu, em âmbito federal, o Programa de Integração da Educação Profissional com a Educação Básica na modalidade Educação de Jovens e Adultos que está em vigor até hoje. Este não mais se restringe ao Ensino Médio, possibilitando integração com o Ensino Fundamental e ampliando a oferta também para as redes estaduais e municipais.

Na constituição da política de integração da Educação Básica com a Educação Profissional na modalidade EJA, ou seja, no PROEJA, vale destacar também a Lei no 11.741, de 16 de julho de 2008, que alterou dispositivos da Lei no 9.394, de 20 de dezembro de 1996, para redimensionar, institucionalizar e integrar as ações da Educação Profissional Técnica, de nível médio, da Educação de Jovens e Adultos e da Educação Profissional e Tecnológica. A presente lei é uma conquista, pois não fica apenas no decreto, já se tem a garantia da integração da EP com a EJA.

O PROEJA busca aliar aumento da escolaridade com formação profissional, oportunizando ao cidadão alternativas para o mundo do trabalho. Olhando pela história da EJA, o PROEJA é uma conquista, pois é resultado de uma luta que perpassava todo o país através dos fóruns de EJA e das organizações sociais. O PROEJA prevê, em sua concepção, a preparação de todos os cidadãos para o mundo do trabalho - isso significa que, além de receber formação para ter acesso ao emprego, o estudante deste Programa deve ter conhecimentos suficientes para uma gestão autônoma e empreendedora, não somente sobre os bens econômicos externos, como também para sua família e para sua vida pessoal (Brasil, 2009). Da mesma forma, através do PROEJA, busca-se a criação de itinerários formativos e uma maneira de atrair os jovens e adultos à escola. Nesse sentido, a instalação dos Institutos Federais de Educação e a crescente criação de campus em todo o Brasil demonstram a possibilidade de as pessoas, independentemente da idade, construírem itinerários formativos e oportunidades de formação profissional. Os cursos que primeiro foram instalados, a partir de 2006 e 2007, na rede federal, foram os de PROEJA Médio, em sua maioria integrados.

Já a partir do ano de $2009^{8}$, tem-se o PROEJA FIC, que foi lançado pela SETEC/MEC com a possibilidade de ampliar para toda a Educação Básica, através da parceria da Rede Federal com os

\footnotetext{
7 Vale registrar também que Moura \& Henrique (2012, p. 119) no artigo "PROEJA: entre desafios e possibilidades" consideram importante também as "mudanças na equipe dirigente da SETEC, no último trimestre de 2005, e o novo grupo mostrou-se sensível às críticas generalizadas provenientes do meio acadêmico e da Rede Federal de EPT. Desses fatos, resultaram alterações substantivas nos rumos da implantação do PROEJA na direção da construção de uma base sólida para a sua sustentação".

8 Segundo o Livro "PROEJA FIC - Educação Inicial e Continuada", que faz parte da coleção Cadernos PROEJA II, Especialização/ Rio Grande do Sul (2010), no Rio Grande do Sul, apresentaram propostas à Carta Convite os campi de Bento Gonçalves, Passo Fundo, Alegrete, São Vicente do Sul, Santa Rosa, Júlio de Castilhos, Panambi e Santo Augusto. No Documento Base do CERTIFIC (2010), encontra-se o seguinte dado: a partir de 2010, a Carta Convite da SETEC/MEC, para implantação do PROEJA FIC, possibilitará a abertura de aproximadamente 16 mil vagas em 57 campus da Rede Federal de Educação, Ciência e Tecnologia em parceria com 156 municípios brasileiros.
} 
municípios e os sistemas prisionais. O referido Programa surgiu com o Ofício MEC/SETEC no 40, que previa o apoio à Rede Federal para implantação de cursos de formação inicial e continuada integrados com o Ensino Fundamental na modalidade da Educação de Jovens e Adultos, nos municípios brasileiros e nos estabelecimentos penais. A seguir, a descrição das ações contidas na Carta Convite:

A - Formação continuada de profissionais para implantação dos cursos PROEJA FIC:

1) Docentes, profissionais da educação, técnicos e gestores que estarão envolvidos na implantação e desenvolvimento dos cursos nas escolas municipais.

2) Docentes, profissionais da segurança pública, técnicos e gestores que estarão envolvidos na implantação e desenvolvimento dos cursos nos estabelecimentos penais.

B - Implantação dos cursos PROEJA FIC.

C - Produção de material pedagógico para os cursos PROEJA FIC.

D - Monitoramento, estudo e pesquisa com vista a contribuir para a implantação e consolidação de espaços de integração das ações desenvolvidas, bem como de investigação das questões atinentes ao PROEJA, considerando a realidade das escolas municipais ou, conforme o caso, da educação em estabelecimentos penais (BRASIL, 2009, p. 1-2, grifos nosso).

Para Maraschin (2015, p. 122), este projeto, "por exigir dos proponentes estas ações mostrou amadurecimento da proposta anterior e propiciou uma maior atenção ao trabalho pedagógico, visto que contempla a formação inicial como uma de suas ações e exigências para implementação do Programa". Também o Documento Base "PROEJA Formação Inicial e Continuada/Ensino Fundamental" sintetiza, logo na apresentação, que, pelo PROEJA:

O que se aspira é uma formação que permita a mudança de perspectiva de vida por parte do aluno; a compreensão das relações que se estabelecem no mundo do qual ele faz parte; a ampliação de sua leitura de mundo e a participação efetiva nos processos sociais. Enfim, uma formação plena. Para tanto, o caminho escolhido é o da formação profissional aliada à escolarização, tendo como princípio norteador a formação integral (Brasil, 2007, p.5).

Ainda na construção de uma política de EJA integrada à EP, no ano de 2010, tem-se o lançamento da Rede Nacional de Certificação Profissional e Formação Inicial e Continuada - Rede CERTIFIC - , que foi uma política pública de inclusão social que se instituiu, através da articulação do Ministério da Educação - MEC - e Ministério do Trabalho e Emprego - MTE - em cooperação com as instituições/organizações que a constituem. A implantação da Rede CERTIFIC atendeu ao que prevê o Art. 41 da Lei № 9.394/96, Lei de Diretrizes e Bases da Educação Nacional (LDB), o Parecer CNE/CEB 16/99, do Conselho Nacional de Educação, o Parecer № 40/2004, do Conselho Nacional de Educação, o § 2ㅇ do Art. 2ㅇd da Lei № 11.892, de 28 de dezembro de 2008, e a Portaria Interministerial $n^{\circ} 1.082$, de 20 de novembro de 2009. Na página da Secretaria de Educação Profissional, encontra-se a seguinte finalidade da Rede:

A Rede Nacional de Certificação Profissional e Formação Inicial e Continuada - Rede CERTIFIC constitui-se como uma Política Pública de Educação Profissional e Tecnológica voltada para o atendimento de trabalhadores, jovens e adultos que buscam o reconhecimento e certificação de saberes adquiridos em processos formais e não formais de ensino-aprendizagem e formação inicial 
e continuada a ser obtido através de Programas Interinstitucionais de Certificação Profissional e Formação Inicial e Continuada - Programas CERTIFIC - (SETEC, 2011).

Conforme o Documento Base da Rede CERTIFIC, com título "Orientações para a implantação da Rede CERTIFIC", o Programa foi criado devido à necessidade de consolidação de uma política pública de reconhecimento de saberes e formação inicial e continuada para fins de certificação profissional e elevação de escolaridade de milhares de trabalhadores (Brasil, 2010).

Dessa forma, o Governo brasileiro sob a perspectiva de ação cooperada para a ampliação da oferta de programas educacionais inclusivos institui a Rede CERTIFIC com a perspectiva de atendimento às principais demandas decorrentes do atual contexto de desenvolvimento econômico e social do país. Entre elas a garantia de gratuidade aos trabalhadores nos processos de certificação profissional e nos cursos das instituições de educação profissional, permitindo-os usufruir dos bens culturais e tecnológicos disponíveis (Brasil, 2010, p. 5).

Nesse contexto, a Rede CERTIFIC é mais uma ação do governo federal, via SETEC/MEC, que tem como objetivo a criação e a implantação de programas interinstitucionais de certificação profissional e formação inicial e continuada para o atendimento a trabalhadores, jovens e adultos que busquem a formação e/ou a avaliação, reconhecimento e certificação de saberes adquiridos em processos formais, ou não formais de ensino (Brasil, 2010). Pelos documentos orientadores, percebe-se que o participante do CERTIFIC pode, conforme sua escolarização, ser direcionado a um curso de Alfabetização, PROEJA, técnico subsequente ou tecnólogo.

Dessa forma, de 2005 a 2010, do PROEJA Médio ao CERTIFIC, pode-se constatar, analisando os documentos bases uma evidência paradoxal: a publicação de políticas educacionais aliando trabalho e educação, denotando empenho em promover uma política educacional para jovens e adultos, por um lado; por outro, relativo e até pouco esforço na consolidação dessa política por parte das instituições e pessoas (Maraschin, 2015). Já a partir de 2011 o governo lança um novo programa - o Programa Nacional de Acesso ao Ensino Técnico e Emprego (PRONATEC) - criado com o objetivo de ampliar a oferta de cursos de Educação Profissional e Tecnológica. São objetivos do Programa:

- $\quad$ expandir, interiorizar e democratizar a oferta de cursos de Educação Profissional Técnica de nível médio e de cursos de formação inicial e continuada ou qualificação profissional presencial e a distância;

- $\quad$ construir, reformar e ampliar as escolas que ofertam Educação Profissional e Tecnológica nas redes estaduais;

- $\quad$ aumentar as oportunidades educacionais aos trabalhadores por meio de cursos de formação inicial e continuada ou qualificação profissional;

- $\quad$ aumentar a quantidade de recursos pedagógicos para apoiar a oferta de Educação Profissional e Tecnológica;

- $\quad$ melhorar a qualidade do Ensino Médio (BRASIL, 2011, art. 1ㅇ).

Esse Programa é visto como concorrente do PROEJA, porque passa a financiar vários cursos, que não poderiam ser articulados à EJA e desenvolvendo prioritariamente cursos rápidos (chamados FIC) na modalidade concomitante. Acontece, então, um novo esforço conjunto dos 
movimentos sociais, fóruns de EJA e pesquisadores da educação e trabalho a demandar investimentos em EJA. Nesse contexto, a partir da Portaria $N^{\circ} 168$, de 07 de março de 2013, é possível às instituições ofertarem o Programa para o público da EJA, criando o que chamamos de PRONATEC EJA.

Nesse caminho, ainda é importante destacar duas legislações que começam a vigorar nos anos seguintes e representam muito na configuração da EJA integrada à EP. A primeira é a Lei № 13.005 de 24 de junho de 2014, que aprova o Plano Nacional de Educação - PNE 2014-2024 - , o qual, na meta 10 , assegura que sejam oferecidas, no mínimo, $25 \%$ das matrículas de EJA, nos ensinos Fundamental e Médio, na forma integrada à Educação profissional. Essa ação é vista como uma grande vitória, mas a segunda, que é a Lei № 13.415, de 16 de fevereiro de 2017, que institui a Política de Fomento à Implementação de Escolas de Ensino Médio em Tempo Integral e promove significativas mudanças no Ensino Médio é considerada um retrocesso. Nesta última, não se percebe o fomento à EJA.

Sendo assim, a partir das legislações e dos programas implementados, questiona-se como a política de EJA configurou-se na prática dos Institutos Federais? A investigação se deu na realidade de dois campi de cada Instituto Federal do RS. Um mais antigo na oferta e outro mais recente.

\section{A REALIDADE DA POLÍTICA DO PROEJA NOS INSTITUTOS FEDERAIS DO RIO GRANDE DO SUL}

O estudo de Maraschin (2015, p. 285) destaca que o movimento dos cursos PROEJA no Rio Grande do Sul" "constituiu-se em movimentos históricos diferentes, característicos a cada realidade e a cada organização de gestão e às ações e relações construídas pelos sujeitos". A seguir, salientam-se aspectos indicados na pesquisa acerca da realidade de seis campi pesquisados.

O Campus de Jaguari tem seu primeiro curso de PROEJA no ano de 2014 e é ofertado dentro da especificidade Educação do Campo e Pedagogia de Alternância. O Campus já tinha a oferta de um curso em que os estudantes se formaram em 2013, ligado ao Campus de São Vicente do Sul do mesmo instituto. Os estudantes que realizam o curso têm vinculação ao Pronatec Mulheres Mil ${ }^{10}$ e alguns também tinham realizado o PROEJA FIC.

O Campus de Jaguari possui a particularidade dos cursos ligados à área da Educação do Campo, que é proposta da instituição, pois oferece cursos integrados na proposta da Pedagogia da Alternância e também a Licenciatura em Educação do Campo. Devido à distância do campus, uma das dificuldades tem sido a permanência dos estudantes em relação à necessidade de transporte.

\footnotetext{
${ }^{9}$ Na pesquisa realizada dos três Institutos do Rio Grande do Sul, um oferta o PROEJA em todos os seus campi, já os outros dois ofertam na metade de seus campi.

10 O Programa Mulheres Mil é uma das ações do PRONATEC EJA.
} 
No Campus de Alegrete, o PROEJA é ofertado desde 2007, logo após a instituição do Decreto, referendado por várias políticas que foram destacadas na seção anterior, entre elas: PROEJA MÉDIO, PROEJA FIC e CERTIFIC. Segundo a diretora do campus, o início da oferta foi constituído num movimento de impacto $X$ oportunidade:

Bom, nós começamos aqui com o PROEJA. No 1 o momento, eu lembro, foi um impacto de nós trabalharmos com educação de jovens e adultos, porque se trabalha e se trabalhava com a educação profissional com alunos de Ensino Médio. Nós já tínhamos uma trajetória de ensino superior - com os dois tecnólogos. Mas trabalhar com a Educação de Jovens e Adultos gerou certo desconforto e uma preocupação: bom e agora? Mas, na época, claro que a gestão entendeu, como eu também entendo, que é uma grande oportunidade, é a oportunidade de dar a estas pessoas que não tiveram na idade própria, condições de seguir seus estudos e a oportunidade de elevar a escolaridade e melhorar a qualidade de vida. Nós enxergamos como uma excelente oportunidade (Diretora do Campus, grifos nosso).

O Campus de Venâncio Aires oferta cursos PROEJA desde 2010 e tem o propósito de construir um campus diferente. Organizaram uma proposta curricular por áreas de conhecimento. A ligação do PROEJA, a "inclusão social" apareceu na fala do diretor: "é instituição que tem que fazer uma inclusão social, então nós, como educadores, temos que aprender a fazer inclusão social. Não sabemos fazer, sabemos selecionar os melhores," (Diretor do Campus) e na dos professores "para mim o PROEJA é inclusão acima de tudo" (Grupo Focal Professores) e na dos estudantes, "estamos ficando mais exigentes também (risos). Estamos vendo a vida com outros olhos. Vimos o futuro, tínhamos aquele mundinho mais pequeno, como somos do interior, tínhamos um mundinho muito pequeno [..]" (Grupo Focal Estudantes).

O Campus da Restinga passou a ofertar o PROEJA a partir de 2010 e, consoante o diretor, a trajetória constituiu-se em um movimento de resistência, com muitas "discussões":

No começo foi uma resistência bem grande do corpo docente de aceitar esse desafio de tocar o PROEJA. As pessoas não conheciam muito bem como funcionava. O próprio currículo integrado em si... Então, acho que foi quase um ano de discussões sobre qual seria o eixo pra gente tocar o curso depois. Qual seria, após escolha do eixo, o melhor curso dentro daquele eixo e montar o projeto de curso. Tudo isso feito de forma colaborativa. (Diretor do Campus, grifos nosso).

O processo seletivo da instituição foi muito destacado, pois é um processo que, na percepção dos professores, objetiva "vincular o estudante à instituição", pois propicia o espaço para eles conhecerem a escola, os cursos, os professores. Nessa ação, o estudante tem a oportunidade de decidir se quer mesmo estudar neste espaço.

Na continuidade, destaca-se o Campus de Bento Gonçalves, que ofertou desde 2007, e que, nos últimos anos, não está mais ofertando a modalidade. Os professores construíram o seguinte diálogo sobre o PROEJA e o PRONATEC:

Part.: O PRONATEC é uma política governamental que está substituindo o PROEJA. Tanto é que o PROEJA, em nível de políticas financeiras, está tendo uma menor valorização. Part.: E agora com o incentivo, várias coisas estão acontecendo. Part.: E ainda não conseguiram se integrar. Part. Não, realmente o foco do governo agora é o PRONATEC. Part. Inclusive, os nossos próprios alunos reconhecem isso: "Professora, olha quanta coisa você faz com o PRONATEC e não se faz nada de 
política e não se faz mais em relação ao PROEJA." Então, as primeiras turmas eram muito valorizadas. Em 2006, percebia-se isso. $O$ governo dando estímulos, faziam-se muitos encontros, muitos trabalhos. E aquilo foi esquecendo. (Grupo Focal Professores, grifos nosso)

Considerando o fragmento acima, constata-se que o discurso dos professores põe em relevo a realidade do processo de instituição da política de EJA, visto que, neste estudo, foi apontado que o PROEJA passa a enfraquecer com a implementação do PRONATEC. É o que se observou na prática, pois os professores ainda comentaram sobre a obrigatoriedade da oferta: até tinha uma época que era obrigado a ter PROEJA, agora, ultimamente, o governo não está mais obrigando a gente a ter essa modalidade. Então, a gente já vê que está acontecendo uma mudança do tipo, de qual é o foco do governo (Grupo Focal Professores, grifos nosso).

Assim, questiona-se o que faz uma instituição, que já tem quase uma década de oferta da modalidade e que ofertou também PROEJA FIC, mudar de foco, cancelar a oferta? Seria a falta de continuidade de um trabalho pedagógico ou seria a influência das políticas mesmo? Após realizar o estudo, analisar o discurso dos interlocutores da pesquisa, passou a acreditar-se que a resposta para tais perguntas está relacionada à falta conhecimento dos professores sobre a legislação dos Institutos Federais e da oferta de cursos integrados e de EJA na Rede.

Para finalizar a amostragem da realidade dos cursos PROEJA do RS, apresenta-se o histórico do Campus de Sapucaia do Sul, que é o mais antigo na oferta de cursos de EJA, inclusive se envolvendo com a oferta antes do Decreto do PROEJA ${ }^{11}$.

Eu só queria lembrar de que o PROEJA não inventou a roda, a nossa história com a EJA é anterior ao PROEJA. Este campus tem uma história de seis, sete anos com o EMA, Educação Média de Adultos, que é para maiores de 25 anos. Um curso de êxito, não era política pública, era uma iniciativa do CEFET e que é sempre importante. Não é uma questão de dizer que um é melhor e o outro é pior, mas dizer que a nossa história com o campus está muito marcada por esta trajetória do EMA. O EMA tem marcas muito profundas na comunidade e nos professores também, que começaram, voluntariamente. [...] Nós tínhamos o EMA diurno e noturno, inicialmente, depois ficou só com o noturno, mas o PROEJA tem que ser entendido dentro desse contexto, é uma política pública sim, mas essa política pública surge de um âmbito bem maior. (Grupo Focal Professores C.6, grifos nosso).

O Campus de Sapucaia do Sul, então, foi implementado e constituiu-se neste movimento que precedeu a instituição do PROEJA e envolveu-se com as políticas de formação de trabalhadores, estabelecendo-se como um espaço de luta, de defesa das políticas educacionais:

De uma maneira geral, sempre teve um grupo significativo, assim ou de poucas pessoas muito fortes que entendem esse espaço como um espaço para as políticas também. Então, esse grupo sempre foi muito aceito e teve força também para que fosse implementado e ocorra como vem

\footnotetext{
11 Importante registrar esta realidade das instituições federais de Educação Profissional também relatadas no artigo de Moura \& Henrique (2012, p. 118), conforme o trecho a seguir: “Na esfera político-pedagógica, as poucas IFETs que ofereciam EJA à época da publicação do mencionado Decreto não o faziam na forma integrada à educação profissional. Dentre as experiências registradas na Rede, destacam-se as experiências dos hoje Institutos de Pelotas/RS, Santa Catarina, Espírito Santo, Campos/RJ e Roraima. Entretanto, em nenhum deles havia oferta integrada entre o ensino médio e a educação profissional técnica de nível médio. A maioria das iniciativas estava relacionada apenas à educação básica, enquanto algumas relacionavam educação básica e profissional na forma concomitante."
} 
historicamente ocorrendo. É um espaço de luta, sem dúvida, mas essas pessoas foram muito fortes nesse sentido (Diretora do Campus).

Assim, resultante do estudo realizado, entende-se ter elaborado mais elementos para entender a historicidade da EJA nos Institutos Federais como um processo de muitas frentes, de vários entrelaçamentos e de um movimento que envolve os sujeitos e constrói diferentes experiências (Maraschin, 2019) e que tem muito a ensinar na luta por uma educação de qualidade. Percebeu-se que o PROEJA provoca muitas transformações, tanto nas realidades, como nos sujeitos envolvidos. Tais experiências precisam ser continuamente registradas, pois, desde a instituição do PRONATEC, as políticas de EJA não têm mais fomento e nos últimos anos a EJA ${ }^{12}$ e o PROEJA têm sido silenciados, ou seja, não são nem sequer lembrados pelas gestões do Ministério da Educação.

\section{CONSIDERAÇÕES FINAIS}

A política de Educação de Jovens e Adultos integrada à Educação Profissional constituiu-se, ao longo da história da educação, em uma grande luta no Brasil. Observa-se que, na Rede Federal, houve um grande investimento por parte do governo nos anos de 2007 a 2010, mas atualmente, apesar de legislações que a garantam, esta não vem sendo fomentada. E a última e polêmica Medida Provisória, transformada na Lei 13.415/2017, que institui a Política de Fomento à Implementação de Escolas de Ensino Médio em Tempo Integral, invisibilizou a EJA. Mesmo assim, nesse contexto, observou-se que, entre os campi dos Institutos Federais do Rio Grande do Sul pesquisados, apenas um deixou de ofertar o PROEJA e demonstrou que esse Programa perdeu espaço na instituição para o PRONATEC. Dessa forma, parece ser necessário que, mais uma vez, os movimentos sociais e os fóruns de EJA retomem a organização para demandar investimentos e construção de uma política para escolarização e formação profissional de jovens e adultos.

Cabe reiterar, ainda, que, tanto nas políticas como nas práticas, é necessário um cuidado para efetivação de uma política plena de formação de jovens e adultos como direito, aspecto preconizado pelas políticas mais emancipatórias, pois se percebem diferentes sentidos e concepções de fundamentos dos programas desenvolvidos de 2005 a 2011, e esses sentidos refletem no cotidiano dos cursos. Revela-se aí que, ora as disputas fazem avançar as políticas e as práticas, ora elas retrocedem, de acordo com o movimento constatado por Maraschin (2015), em sua tese, com o título: "Dialética das disputas: trabalho pedagógico a serviço da classe trabalhadora?".

Importante registrar, neste processo contraditório, que os cursos analisados apresentam significativas experiências para gestores, professores e estudantes, como afirma uma diretora entrevistada - "só quem trabalha com o PROEJA ou quem vivencia o que é o PROEJA sabe da importância dessa modalidade" (Diretora do Campus de Alegrete). Então, diante disso, cabe dar

\footnotetext{
12 O Ministério da Educação, no governo de Jair Bolsonaro destituiu a SECADI, que era a Secretaria do MEC que cuidava das políticas de alfabetização, inclusão e educação de jovens e adultos.
} 
continuidade a esses movimentos em prol da educação e trabalho de jovens e adultos, tendo em vista ser uma luta histórica, associada aos movimentos de trabalhadores, em um país onde as desigualdades sociais são cada vez mais evidentes.

\section{REFERÊNCIAS BIBLIOGRÁFICAS}

BRASIL. (2009). Ministério da Educação. Documento Base PROEJA - Ensino Médio. Brasília: MEC.

BRASIL. (2007). Documento Base PROEJA Formação Inicial e Continuada/Ensino Fundamental. Brasília: MEC.

BRASIL. (2010). Orientações para a implantação da Rede Nacional de Certificação Profissional e Formação Inicial e Continuada - Rede CERTIFIC/ organizado por Luiz Augusto Caldas Pereira e Sônia da Costa. Ministério da Educação, Secretaria de Profissional e Tecnológica. Brasília: MEC, SETEC, 96 p, 2010.

BRASIL. (1996). Lei 9394/96 de 20.12.96 - Lei de Diretrizes e Bases da Educação Nacional. Brasília (DF): Diário Oficial da União. n² 248 de 23.12.96.

BRASIL. (2008) Lei no 11.892, 29 de dezembro de 2008. Institui a Rede Federal de Educação Profissional, Científica e Tecnológica, cria os Institutos Federais de Educação, Ciência e Tecnologia e dá outras providências. Disponível em: http://www.planalto.gov.br Consultado em: 10 de agos. de 2010.

BRASIL. (2000). Conselho Nacional da Educação. Câmara de Educação Básica, Parecer № 11, de maio.

BRASIL. (2005). Decreto no 5.478, de 24 de junho de 2005. Institui, no âmbito das instituições federais de educação tecnológica, o Programa de Integração da Educação Profissional ao Ensino médio na Modalidade de Educação de Jovens e Adultos - Proeja. Brasília, DF

BRASIL. (2006). Decreto no 5.840, de 13 de julho de 2006. Institui, no âmbito federal, o Programa Nacional de Integração da Educação Profissional com a Educação Básica ao na Modalidade de Educação de Jovens e Adultos - Proeja. Brasília, DF

BRASIL. LEI 13.005 de 25 de junho de 2014. Aprova o Plano Nacional de Educação e dá outras providências.

BRASIL. (2008). Lei 11.741 de 16 de julho de 2008. Altera dispositivos da Lei no 9.394, de 20 de dezembro de 1996, que estabelece as diretrizes e bases da educação nacional, para redimensionar, institucionalizar e integrar as ações da educação profissional técnica de nível médio, da educação de jovens e adultos e da educação profissional e tecnológica.

BRASIL. (2017) Lei 13.415 de 16 de fevereiro de 2017. Altera as Leis nํㅗ 9.394, de 20 de dezembro de 1996, que estabelece as diretrizes e bases da educação nacional, e 11.494, de 20 de junho 2007, que regulamenta o Fundo de Manutenção e Desenvolvimento da Educação Básica e de Valorização dos Profissionais da Educação, a Consolidação das Leis do Trabalho - CLT, aprovada pelo Decreto- 
Lei no 5.452, de 1o de maio de 1943, e o Decreto-Lei no 236, de 28 de fevereiro de 1967; revoga a Lei no 11.161, de 5 de agosto de 2005; e institui a Política de Fomento à Implementação de Escolas de Ensino Médio em Tempo Integral.

BRASIL. (2009). Ministério da Educação. Ofício Circular no 40. Brasília: MEC.

BRASIL. (2009). PORTARIA INTERMINISTERIAL № 1.082, DE 20 DE NOVEMBRO DE 2009. Dispõe sobre a criação da Rede Nacional de Certificação Profissional e Formação Inicial e Continuada Rede CERTIFIC.

BRASIL. (2011) Lei $N^{\circ} 12.513$, de 26 de Outubro de 2011. Programa Nacional de Acesso ao Ensino Técnico e Emprego - PRONATEC, altera as Leis n. 7.998, de 11 de janeiro de 1990, n. 8.121, de 24 de julho de 1991 e n. 10.260, de 12 de julho de 2001.

BRASIL. (2013). Portaria N 168, de 07 de março de 2013. Dispõe sobre a oferta da Bolsa-Formação no âmbito do Programa Nacional de Acesso ao Ensino Técnico e Emprego - Pronatec, de que trata a Lei no 12.513, de 26 de outubro de 2011, e dá outras providências.

FERREIRA, L. S.( 2018). "Trabalho Pedagógico na Escola: do que se fala?” In: Educação e. Realidade. Porto Alegre, vol.43, n.2 , p.591-608.

FERREIRA, L. S.; MARASCHIN, M. S.; AMARAL, C. L. do; FIORIN, B. (2014). Grupos de interlocução como técnica de produção e sistematização na pesquisa em educação. Revista Diálogo Educacional, Curitiba, v 14, n 41, p. 191-209, jan./abr.

GATTI, B. A. (2002) Grupo focal na pesquisa em ciências sociais e humanas. Brasília: Liber Livro.

KUENZER, A. Z.. "A Educação Profissional nos anos 2000: a dimensão subordinada das políticas de inclusão”. In: Educação e Sociedade, Campinas, vol. 27, n. 96 - Especial, out. 2006, p. 877-910.

MACHADO, M. M.. (2009). A educação de jovens e adultos no Brasil pós-Lei no 9.394/96: a possibilidade de constituir-se como política pública. Em Aberto, Brasília, v. 22, n. 82, p. 17-39, nov.

MANFREDI, S. M.. Educação Profissional no Brasil. São Paulo: Cortez, 2002.

MARASCHIN, M. S. (2015). Dialética das Disputas: trabalho pedagógico a serviço da classe trabalhadora? Tese (doutorado) - Universidade Federal de Santa Maria, Centro de Educação, Programa de Pós Graduação em Educação, 2015.

MARASCHIN, M. S. (2019). Trabalho Pedagógico na Educação Profissional: o Proeja entre disputas, políticas e experiências. Curitiba: Appris.

MOURA, D. H. \& HENRIQUE, A. L. S. (2012). PROEJA: entre desafios e possibilidades. Revista Holos. V. 2. Disponível em < http://www2.ifrn.edu.br/ojs/index.php/HOLOS/article/view/914> Acesso em 02/04/2020.

PACHECO, E. (2012). Perspectivas da Educação Profissional Técnico de Nível Médio: Propostas de diretrizes curriculares. São Paulo, SP: Moderna. 
VENTURA, J. P. (2008) Educação de Jovens e Adultos ou Educação da Classe Trabalhadora? Concepções em Disputa na contemporaneidade brasileira. Tese (Doutorado em Educação). Niterói: Faculdade de Educação, Universidade Federal Fluminense. 